\title{
The Survival of Escherichia coli in Nitrogen Atmospheres under Changing Conditions of Relative Humidity
}

\author{
By C. S. COX \\ Microbiological Research Establishment, Porton Down, \\ near Salisbury, Wiltshire
}

(Received 11 January, 1966)

\begin{abstract}
SUMMARY
The consequence of relative humidity $(\mathrm{RH})$ changes before collection of bacterial aerosols are described; it is shown how Escherichia coli (B, commune), but not $\boldsymbol{E}$. coli Jepp, gave good survival over the range 100-20\% RH provided that the following conditions applied: (1) a pure nitrogen atmosphere; (ii) a protective agent in the spray fluid; (iii) sucrose in the collecting fluid; (iv) an $\mathrm{RH}$ change to $100 \%$ or to a nominal $30 \%$ (depending upon the experimental conditions) before collection of the aerosol. Differences in survival of $\boldsymbol{E}$. coli commune sprayed from suspension in solutions of raffinose into an atmosphere of nitrogen which were previously attributed to the effect of raffinose concentration in the spray fluid were found to be caused by the use of variant organisms.
\end{abstract}

\section{INTRODUCTION}

Previous papers (Cox, 1966; Cox \& Baldwin, 1966) showed that the survival of Escherichia coli as an aerosol was greatly enhanced at low relative humidity (RH) when nitrogen replaced air. In the high $\mathrm{RH}$ range, regions of marked aerosol instability occurred for the bacteria sprayed from suspension in distilled water, while the addition of a protective agent altered both the size and the $\mathrm{RH}$ value of the minima in plots of survival versus RH. The possibility was considered that a shift in RH from high (unstable) to low (stable) values before collection might indicate whether the death of $\boldsymbol{E}$. coli occurred in the aerosol at high humidity or as a result of the collection technique. The present paper gives the results obtained and shows the extent to which decrease of survival values may be attributed to the method of sampling. In previous work (Cox, 1966) the effect of the protective agent appeared markedly to depend on its concentration for $E$. coli commune, whereas for E. coli (в, Jepp) the effect was much less marked. The possibility that the apparent effect of concentration of protective agent might have been associated with a change of stock culture was also examined, even though different stock cultures gave suspensions having very similar survival characteristics under the conditions of test when sprayed from distilled water.

\section{METHODS}

The techniques used were as previously reported (Cox, 1966), with the addition that chambers of 21 . capacity as in Fig. 1 were used to bring about the changes in the RH shifts. Partial filling of the chambers and wetting of the muslins, with 
distilled water or with saturated lithium chloride $\left(\mathrm{LiCl}_{2}\right)$ solution, enabled $\mathrm{RH}$ values of approximately 100 and $30 \%$, respectively, to be achieved. The value of $30 \% \mathbf{R H}$ is in doubt since this was the value achieved when 121 . wet nitrogen/ min. flowed through the chamber. In equilibrium conditions an $\mathbf{R H}$ value of $12 \%$ should be achieved; since the aerosol cloud remained static in the chambers for 30 sec. before collection the true value of $\mathrm{RH}$ will have been between these two extreme values. This $\mathrm{RH}$ range corresponded to a plateau region of good survival for Escherichia coli in nitrogen (Cox, 1966). The chambers were maintained under an atmosphere of nitrogen $(>99.9 \%)$ at all times.

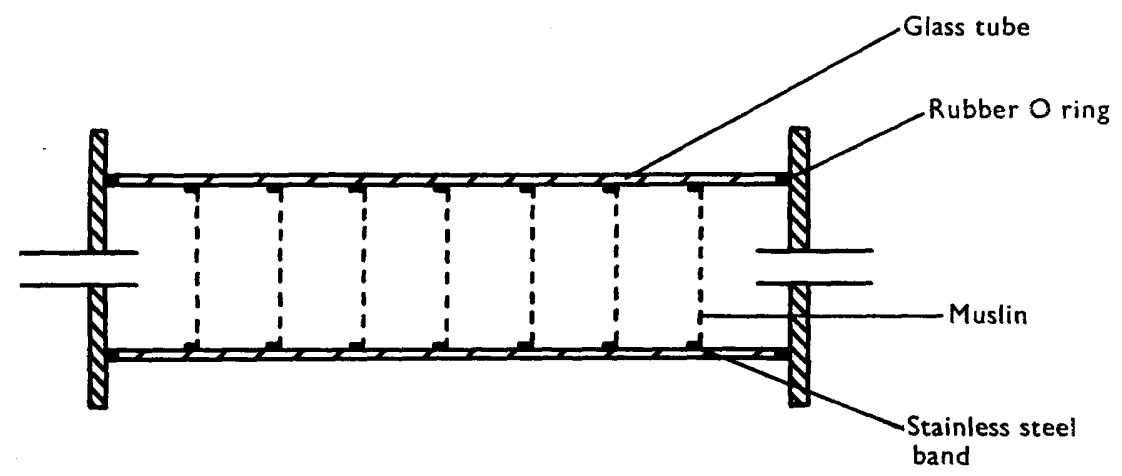

Fig. 1. Chamber of 21 . capacity used for making relative humidity changes.

\section{RESULTS}

Figure 2 shows the survival of Escherichia coli commune 2 when sprayed into nitrogen from 0.13 M-raffinose in distilled water (added to the bacteria immediately before spraying), at an aerosol age of $25 \mathrm{~min}$. for collection by raised impinger (May \& Harper, 1957) into phosphate buffer and into M-sucrose + phosphate buffer. Similar to previous results (Cox, 1966) collection in phosphate buffer was marked by instability within the range $\mathbf{7 2 - 8 6 \% ~} \mathbf{R H}$, whereas collection in $\mathrm{M}$-sucrose + phosphate buffer revealed only one clear minimum at RH 81-82\%. However, with this variant of $\boldsymbol{E}$. coli commune the extent of the instability was less than that previously observed.

Figures 3 and 4 show the effect of changing the RH of the nitrogen atmosphere either to $100 \%$ or to $30 \%$ before collecting the aerosol. In general phosphate buffer and $\mathrm{m}$-sucrose + phosphate buffer gave similar results outside the unstable zone of 72-86 \% RH. In the unstable zone phosphate buffer remained inferior to M-sucrose + phosphate buffer when the shift was to $30 \% \mathbf{R H}$, but the difference was smaller when the shift was to RH $100 \%$. Suspensions prepared from a third stock culture of Escherichia coli commune gave similar results under static and changing $\mathbf{R H}$ conditions.

Table 1 includes results for three strains of Escherichia coli when sprayed into nitrogen from distilled water and from $0 \cdot 13 \mathrm{M}$-raffinose in distilled water (added to the bacteria immediately before spraying) at an aerosol age of $25 \mathrm{~min}$. The test $\mathrm{RH}$ values were those corresponding to minima in the plots of survival versus $R H$, or were at $\mathbf{3 0} \% \mathbf{R H}$ where the stability was much greater. The data agree with that 
previously published (Cox, 1966) and show that when sprayed from distilled water RH changes before collection did not markedly effect the survival of $\boldsymbol{E}$. coli (в, Jepp) stored at RH $85 \%$. However, for $E$. coli commune 2 at RH $81 \%$ a change to $100 \%$, but not to $30 \%$, produced a large increase in the survival in both collecting fluids. When the organisms were sprayed from raffinose the pattern of results was

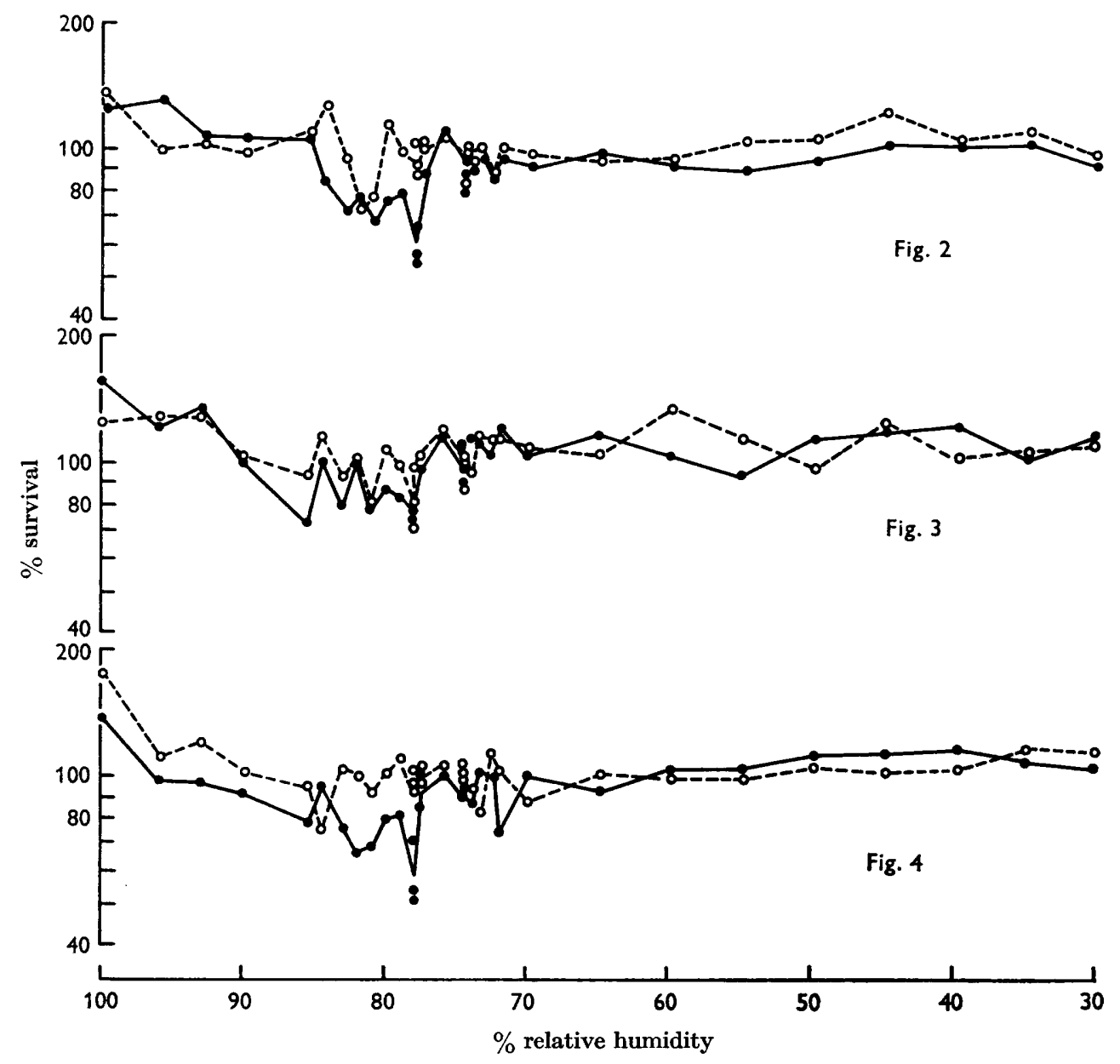

Figs. 2-4. Survival of Escherichia coli commune 2 in nitrogen, sprayed from $0 \cdot 13$ M-raffinose at an aerosol age of $25 \mathrm{~min}$. , Collection in phosphate buffer; $O$, collection in $\mathrm{M}$-sucrose t phosphate buffer. Fig. 2. At the storage relative humidity. Fig. 3. At the storage relative humidity followed by a change in relative humidity to $100 \%$ before collection. Fig. 4. At the storage relative humidity followed by a change in relative humidity to $30 \%$ before collection.

more complex. A change from RH 83 to $100 \%$, but not to $30 \%$, eliminated the difference between collection in the two fluids for $E$. coli B and gave $100 \%$ survival. For $\boldsymbol{E}$. coli Jepp neither a change to RH $\mathbf{1 0 0} \%$ nor to $\mathbf{3 0} \%$ gave enhanced survival for either collecting fluid. $E$. coli commune 2 gave $100 \%$ survival when the RH changed to $100 \%$, but the change to $30 \%$ resulted in survival being dependent upon collecting fluid. 
For aerosols stored at a controlled RH value of $30 \%$ no really marked effect of changes of RH occurred for Escherichia coli B and commune 2. However, for $\boldsymbol{E}$. coli Jepp, as might be expected from its instability at high RH (Cox, 1966) a change to RH $100 \%$ caused a rapid decrease of survival. The results for $E$. coli Jepp also showed the previously reported (Cox, 1966) poorer survival in M-sucrose + phosphate buffer than in phosphate buffer alone which occurred at low RH, but not at high RH; these results contrast with those obtained with $E$. coli B and commune at low RH.

Table 1. The influence on stored aerosols of Escherichia coli in nitrogen at $26.5^{\circ}$ of relative humidity changes before collection

\begin{tabular}{|c|c|c|c|c|c|c|c|c|}
\hline \multirow[b]{3}{*}{ Strain of $E$. coli } & \multirow{3}{*}{$\begin{array}{l}\text { Spray } \\
\text { fluid }\end{array}$} & \multirow{3}{*}{$\begin{array}{l}\text { Percentage } \\
\text { RH for } \\
\text { storage }\end{array}$} & \multicolumn{6}{|c|}{ Percentage survival } \\
\hline & & & \multicolumn{2}{|c|}{ At storage $\mathbf{R H}$} & \multicolumn{2}{|c|}{ At $100 \% \mathbf{R H}$} & \multicolumn{2}{|c|}{ At $\mathbf{3 0} \% \mathbf{R H}$} \\
\hline & & & PB* & PBS* & PB & PBS & PB & PBS \\
\hline $\mathbf{B}$ & $\mathrm{D}_{\dagger}^{\dagger}$ & $\begin{array}{l}85 \\
30\end{array}$ & $\begin{array}{l}0 \cdot 5 \\
80\end{array}$ & $\begin{array}{r}0 \\
77\end{array}$ & $\begin{array}{r}0 \\
65\end{array}$ & $\begin{array}{r}2 \\
35\end{array}$ & $\begin{array}{r}0 \\
85\end{array}$ & $\begin{array}{r}0 \\
61 .\end{array}$ \\
\hline Jepp & $\mathbf{D}$ & $\begin{array}{l}85 \\
30\end{array}$ & $\begin{array}{r}0 \\
50\end{array}$ & $\begin{array}{l}0 \cdot 5 \\
7\end{array}$ & $\begin{array}{c}0 \cdot 9 \\
9\end{array}$ & $\begin{array}{l}0.4 \\
0.9\end{array}$ & $\begin{array}{r}0 \\
42\end{array}$ & $\begin{array}{l}0 \cdot 2 \\
3\end{array}$ \\
\hline commune 2 & $\mathbf{D}$ & $\begin{array}{l}81 \\
30\end{array}$ & $84^{3 \cdot 3}$ & $\begin{array}{r}6 \\
82\end{array}$ & $\begin{array}{l}18 \\
83\end{array}$ & $\begin{array}{l}21 \\
70\end{array}$ & $\begin{array}{r}1 \\
82\end{array}$ & 90 \\
\hline B & $\mathbf{R} \ddagger$ & $\begin{array}{l}83 \\
30\end{array}$ & $\begin{array}{r}39 \\
110\end{array}$ & $\begin{array}{l}102 \\
113\end{array}$ & $\begin{array}{l}100 \\
124\end{array}$ & $\begin{array}{l}100 \\
127\end{array}$ & $\begin{array}{r}38 \\
104\end{array}$ & $\begin{array}{l}100 \\
105\end{array}$ \\
\hline Jepp & $\mathbf{R}$ & $\begin{array}{l}82 \\
30\end{array}$ & $\begin{array}{c}2 \cdot 5 \\
97\end{array}$ & $\begin{array}{l}15 \\
22\end{array}$ & $\begin{array}{r}1 \\
64\end{array}$ & $\begin{array}{r}2 \\
28\end{array}$ & $\begin{array}{r}5 \\
94\end{array}$ & $\begin{array}{l}15 \\
25\end{array}$ \\
\hline commune 2 & $\mathbf{R}$ & $\begin{array}{l}82 \\
30\end{array}$ & $\begin{array}{l}77 \\
94\end{array}$ & $\begin{array}{r}73 \\
100\end{array}$ & $\begin{array}{r}99 \\
115\end{array}$ & $\begin{array}{l}100 \\
114\end{array}$ & $\begin{array}{r}66 \\
104\end{array}$ & $\begin{array}{l}108 \\
117\end{array}$ \\
\hline
\end{tabular}

* PB = phosphate buffer collecting fluid; PBS $=$ M-sucrose + phosphate buffer collecting fluid. $\dagger \mathbf{D}=$ distilled water. $\quad \ddagger R=0.13 \mathrm{M}$-raffinose in distilled water added immediately prior to spraying.

\section{DISCUSSION}

The difference in behaviour of Escherichia coli commune when sprayed from $\mathbf{0} \cdot 13$ and $0.3 \mathrm{M}$-raffinose, located outside the cell wall, was previously attributed (Cox, 1966) to the difference in raffinose concentration. From the results of the experiments given in the present paper it now seems to have been caused by the use of stock cultures which contained different variants of $E$. coli commune. These variants were not distinguishable under the conditions of test in aerosol behaviour when sprayed as a suspension in distilled water, but were distinguishable in the presence of raffinose. These findings are perhaps an indication of the subtlety of the action of raffinose as a protective agent. As far as can be judged, each stock culture gave rise to suspensions of bacteria showing consistent behaviour, and it has been possible to achieve similar results for suspensions arising from different stock cultures. The three stock cultures all gave suspensions of bacteria which, when sprayed from raffinose, showed the same trends, namely, good survival at high and low $\mathrm{RH}$ and poorer survival in the $\mathbf{R H} \mathbf{7 2 - 8 6} \%$ region, with minima at 74 and $78 \%$ (and at $81 \% \mathrm{RH}$ for one culture, others not tested at this $\mathrm{RH}$ ). Hence it was the degree of response rather than the response itself which was dependent upon the stock culture 
used. This difference in stock culture so far has not been found for $\boldsymbol{E}$. coli B and Jepp. Dr G. J. Harper (personal communication) has found that $\boldsymbol{E}$. coli commune gives variants.

Previous work (Cox, 1966) showed that part of the survival decrease of Escherichia coli occurred during or following collection by raised impinger (May \& Harper, 1957). Transfer from the unstable relative humidity zone to a stable zone before collection should indicate the proportions in which death occurred in the aerosol and in the impinger. The stable state most easily obtained for E. coli (в, Jepp, commune) was in the region of $\mathbf{R H ~} 30 \%$. A second region near $\mathrm{RH} 100 \%$ was reasonably stable for bacteria protected with raffinose, but not when sprayed from distilled water alone. The results (Table 1) show that a shift to RH $100 \%$ usually increased the survival of $\boldsymbol{E}$. coli B, commune but not of $\boldsymbol{E}$. coli Jepp. A shift to RH $30 \%$ had no significant effect for $\boldsymbol{E}$. coli B and Jepp with either spray fluid; however, for $\boldsymbol{E}$. coli commune sprayed from raffinose, but not distilled water, the shift in RH was beneficial.

Other slight anomalies remain. Since little difference had been found between phosphate buffer and $\mathrm{m}$-sucrose + phosphate buffer as collecting fluids at low RH for Escherichia coli $\mathrm{B}$ and commune, then if an aerosol stored at high $\mathrm{RH}$ were changed to low $\mathrm{RH}$ before collection, it might be expected that the collection difference between phosphate buffer and $\mathbf{m}$-sucrose + phosphate buffer observed at high RH might disappear, but in fact it did not. Escherichia coli Jepp at low RH had shown poorer survival for collection in $\mathbf{M}$-sucrose + phosphate buffer than in phosphate buffer, and the converse was true at high RH (Cox, 1966). Hence, if an aerosol were stored at low $\mathbf{R H}$, then transferred to $\mathbf{R H ~} 100 \%$ before collection it might be expected that $\mathrm{M}$-sucrose + phosphate buffer would be a better collecting fluid than phosphate buffer alone. However, it was not. The collection difference would therefore not seem to be caused simply by water activity differences. Dramatic effects, both of a beneficial and of a detrimental nature, were reported by Cox (1965) and by Silver (1965) for shifts in $\mathrm{RH}$ to $100 \%$ before collection.

Provided that raffinose located outside the cell wall is used to protect Escherichia coli $\mathbf{B}$ and commune and that the necessary collecting fluid is used together with an RH change to either $100 \%$ or $30 \%$, depending upon the conditions, then death at or following collection can be eliminated and good survival can be achieved over the range $\mathbf{R H} 20-100 \%$. For $E$. coli Jepp these procedures are not sufficient to overcome the instability in the region of $\mathrm{RH} 82 \%$.

The author thanks Mr I. H. Silver for his interest and for much helpful discussion, and thanks Mr M. C. Aireton for technical assistance.

\section{REFERENCES}

Cox, C. S. (1965). The mode of action of protecting agents. Ist Int. Symp. on Aerobiology, p. 345. Published by Naval Biological Laboratory, Naval Supply Center, Oakland, California.

Cox, C. S. (1966). The survival of Escherichia coli atomized into air and into nitrogen from distilled water and from solutions of protecting agents, as a function of relative humidity. J. gen. Microbiol. 43, 383. 
Cox, C. S. \& BaLDwin, F. (1966). The use of phage to study causes of loss of viability of Escherichia coli in aerosols. J. gen. Microbiol. 44, 15.

MAY, K. R. \& HARPER, G. J. (1957). The efficiency of various liquid impinger samplers in bacterial aerosols. Br. J. indust. Med. 14, 15.

Silver, I. H. (1965). Viability of micro-organisms using a suspended droplet technique. 1st Int. Symp. on Aerobiology, p. 319. Published by Naval Biological Laboratory, Naval Supply Centre, Oakland, California. 